\title{
Risk of Psychiatric Disorders in Multiple Sclerosis: A Nationwide Cohort Study in an Asian Population
}

\section{Yao-Ching Huang,' Wu-Chien Chien, ${ }^{2-5, *}$ Chi-Hsiang Chung, (iD ${ }^{2-4}$ Hsin-An Chang, ${ }^{6,7}$ Yu-Chen Kao, ${ }^{6,8}$ Fang-Jung Wan, ${ }^{6}$ Shi-Hao Huang, (1D' Ren-Jei Chung, (D) ${ }^{1, *}$ Richard S Wang, (1D ${ }^{9}$ Bing-Long Wang, $\mathbb{D}^{2}, *$ Nian-Sheng Tzeng, $\mathbb{D}^{7,8, *}$ Chien-An Sun ${ }^{10,11}$}

'Department of Chemical Engineering and Biotechnology, National Taipei University of Technology, Taipei, Taiwan; ${ }^{2}$ School of Public Health, National Defense Medical Center, Taipei, Taiwan; ${ }^{3}$ Department of Medical Research, Tri-Service General Hospital, National Defense Medical Center, Taipei, Taiwan; ${ }^{4}$ Taiwanese Injury Prevention and Safety Promotion Association, Taipei, Taiwan ${ }^{5}$ Graduate Institute of Life Sciences, National Defense Medical Center, Taipei, Taiwan;

${ }^{6}$ Department of Psychiatry, Tri-Service General Hospital, School of Medicine, National Defense Medical Center, Taipei, Taiwan; ${ }^{7}$ Student Counseling Center, National Defense Medical Center, Taipei, Taiwan; ${ }^{8}$ Department of Psychiatry, Tri-Service General Hospital, SongShan Branch, National Defense Medical Center Taipei, Taiwan; ${ }^{9}$ Program of Data Analytic and Business Computing, Stern School of Business, New York University, USA; ${ }^{10}$ Department of Public Health, College of Medicine, Fu-Jen Catholic University, New Taipei City, Taiwan; "'Big Data Research Center, College of Medicine, Fu-Jen Catholic University, New Taipei City, Taiwan

*These authors contributed equally to this work

Correspondence: Nian-Sheng Tzeng Department of Psychiatry, School of Medicine, Tri-Service General Hospital, National Defense Medical Center, 325, Section 2, Cheng-Gung Road, Nei-Hu District, Taipei, Taiwan, Republic of China

Tel +886-2-879233। I Ext 17484

Fax +886-2-8792722।

Email pierrens@mail.ndmctsgh.edu.tw

Bing-Long Wang

Department of Public Health, National Defense Medical Center, I 16, Section 6, Minchuan E.

Road, Nei-Hu District, Taipei, Taiwan, Republic of China

Tel +886-980-79495।

Email billwang1203@gmail.com
This article was published in the following Dove Press journal:

Neuropsychiatric Disease and Treatment

Background: Multiple sclerosis (MS) is a demyelinating disease that can damage neurons in the brain and spinal cord and is associated with several psychiatric disorders. However, few studies have evaluated the risk of psychiatric disorders in patients with MS by using a nationwide database. This study investigated the association between MS and the risk of psychiatric disorders.

Methods: Using data from the Taiwan National Health Insurance Research Database from 2000 to 2015, we identified 1066 patients with MS. After adjustment for confounding factors, Fine and Gray's competing risk model was used to compare the risk of psychiatric disorders during 15 years of follow-up.

Results: Of the patients with MS, 531 (4622.86 per $10^{5}$ person years) developed psychiatric disorders; by contrast, 891 of the 3198 controls (2485.31 per $10^{5}$ person years) developed psychiatric disorders. Fine and Gray's competing risk model revealed an adjusted hazard ratio (HR) of $5.044(95 \%$ confidence interval $=4.448-5.870, p<0.001)$ after adjustment for all the covariates. MS was associated with depression, anxiety, bipolar disorder, sleep disorders, schizophrenia, schizophreniform disorder, and other psychotic disorders (adjusted HR: 12.464, 4.650, 6.987, 9.103, 2.552, 2.600, 2.441, and 2.574, respectively; all p < 0.001). Some disease-modifying drugs were associated with a lower risk of anxiety or depression.

Conclusion: Patients with MS were determined to have a higher risk of developing a wide range of psychiatric disorders.

Keywords: multiple sclerosis, psychiatric disorders, depression, anxiety

\section{Introduction}

Although patients with multiple sclerosis (MS) experience considerable challenges and even disability, comprehension of the underlying factors of this disease, including genetics and environmental conditions, has improved. ${ }^{1}$ MS often has negative effects on the patients' quality of life as well as their interpersonal relationships, employment, and social life. ${ }^{2}$ Neuroimaging research have revealed that symptoms can originate from different brain networks, regardless of the pathological substrate, and from disconnections caused by damage to the strategic white matter tracts. ${ }^{3}$

Previous studies have found that some neuropsychiatric disorders are associated with several immune-mediated inflammatory diseases, ${ }^{4}$ such as Guillain-Barre syndrome, ${ }^{5}$ fibromyalgia, ${ }^{6}$ allergic diseases, ${ }^{7}$ and periodontal inflammatory diseases. $^{8-11}$ Psychological stressors related to the inflammatory diseases might also contribute to both psychiatric and physical morbidity, ${ }^{12}$ and several studies have found that MS is associated with depression, anxiety, bipolar disorder, sleep 
disorders, alcohol abuse, substance abuse, and psychosis.${ }^{13,14}$ However, in Taiwan, the prevalence of MS is approximately $2-5$ per $100,000,{ }^{15-17}$ which is much lower than the 10-year prevalence of MS in the United States (149.2309.2 per 100,000). ${ }^{18,19}$ Most of the studies about the association between multiple sclerosis and psychiatric disorders are from Western countries, with higher MS prevalence, including anxiety, depression, bipolar disorder, sleep disorder, alcohol abuse, drug abuse, and psychotic disorder, such as schizophrenia.,13,14,20-23 Other studies have reported that patients with MS to be at risk for some psychiatric disorders including depression ${ }^{24}$ and erectile dysfunction, ${ }^{25}$ but no nationwide population-based study has yet been conducted on the correlations of MS with most of the other aforementioned psychiatric disorders. Therefore, a nationwide cohort study must be executed to determine the association of MS with psychiatric disorders in Taiwan. This explored this topic by applying National Health Insurance Research Database (NHIRD)-derived data in order to determine the psychiatric morbidity of patients with MS in Taiwan.

\section{Methods}

\section{Data Sources}

The National Health Insurance (NHI) program, which is Taiwan's single-payer insurance system, was launched in 1995. As of June 2018, it provided medical coverage for an estimated 23 million individuals ( $>99 \%$ of the population in Taiwan), in collaboration with $97 \%$ of medical providers. ${ }^{26,27}$ Previously executed research has documented the program's details. ${ }^{28-40}$

The NHIRD comprises comprehensive data on patients' sex and their date of birth as well as the prescriptions, dental care, outpatient care, and inpatient care that they have received. In accordance with the Personal Information Protection Act, patient identifiers undergo encryption prior to the release of data for use in research. NHIRD-recorded diagnoses are coded in accordance with the International Classification of Diseases, 9th Revision, Clinical Modification (ICD-9-CM). Board-certified neurologists and board-certified psychiatrists gave all MS diagnoses and all psychiatric disorder diagnoses, respectively. In Taiwan, the diagnosis of MS was according to the McDonald criteria and serial of the revised versions. ${ }^{41-43}$

In the present study, inpatients determined to have received an MS diagnosis (ICD-9-CM code: 340) at discharge during 2000-2015 were identified from the 2- million Longitudinal Health Insurance Database, a subset of the NHIRD. Clinic and hospital reimbursement claims were reviewed by licensed medical record technicians for coding verification. ${ }^{27}$ Senior external specialists in psychiatry and neurology are selected by the National Health Insurance Administration (NHIA) to periodically conduct random reviews of records pertaining to outpatient care visits as well as inpatient claims in order to confirm accurate diagnoses. ${ }^{44}$

\section{Study Design and Sampling}

In our executed population-based, matched-cohort study, we identified from the inpatient data set adults who had recently received an MS diagnosis during the period from January 1, 2000, to December 31, 2015. To restrict our sample to only patients with newly registered MS, we excluded patients who had received an MS diagnosis prior to 2000. Additionally, patients who had received a diagnosis of depressive, bipolar, anxiety, sleep, schizophrenia, schizophreniform disorder, other psychotic disorder, or substance-related disorders (disorders pertaining to alcohol use or illicit drug use) before 2000 were excluded. All patients under the age of 20 years were also excluded so that that only adult patients were included. The patients' catastrophic illness certificates (CICs) were used to ensure the accuracy of the MS diagnosis because in accordance with NHI regulations, patients with a CIC are exempted from copayment for MS-related medical care after their medical records and imaging and laboratory results have been rigorously reviewed. With reference to other research involving the use of the NHIRD to study MS, we estimated patients' follow-up durations by using CIC registration dates as the index dates. ${ }^{45}$ The NHIA review committee assesses applications according to both the Posner criteria and McDonald criteria. ${ }^{46}$ Among the patients included in this study, the average time from the first inpatient diagnosis to the CIC registration date was 14.06 (standard deviation $[\mathrm{SD}]=18.25$ ) days. We excluded patients who had other neurological disorders and were admitted due to conditions that were comparable to $\mathrm{MS}$, including critical illness polyneuropathy, chronic inflammatory demyelinating polyneuropathy, polyneuropathy caused by other diseases (eg, diphtheria or porphyria), critical illness myopathy, acute poliomyelitis, myasthenic syndromes, myasthenia gravis, acute transverse myelitis, or poisoning from drugs or biological substances (Figure 1). 




Figure I The flowchart of study of multiple sclerosis (MS) sample selection from National Health Insurance Research Database in Taiwan.

\section{Ethics}

The tenets of the Declaration of Helsinki were adhered to, following the Code of Ethics of the World Medical Association. Since the identifiable database of individuals included in the NHIRD were all encrypted in order to protect individual privacy, ${ }^{27,47,48}$ the NHI Administration has given general approval for their data to be used in this research. ${ }^{48}$ Because the NHIRD has the advantage of providing a large-scale, longitudinal, reliable dataset, leading to extensive usage for population-based researches in Taiwan. ${ }^{48-51}$ Therefore, the Tri-Service General Hospital's Institutional Review Board ratified our executed study (IRB No. 2-107-05-026); in addition, the necessity of written informed consent from individuals was waived.

\section{Covariates}

The covariates in this study consisted of sex, age group (20-49, 50-64, or $\geq 65$ years), marital status, education $(<12$ years or $\geq 12$ years $)$, monthly income $(<\mathrm{NT} \$ 18,000$,
NT\$18,000-34,999, $\geq$ NT\$35,000), urbanization level (levels 1-4), and region of residence (central, northern, eastern, or southern Taiwan). Population as well as several indicators of development level constituted the basis for the definition of urbanization level; the definition is detailed as follows. Level 1: population of $>1,250,000$ with designated economic, political, metropolitan, and cultural development. Level 2: population of 500,000$1,249,999$ with prominent political, cultural, and economic influence. Level 3: population of 149,999-499,999. Level 4: population of $<149,999$. Usage of the NHI-reimbursed disease-modifying drugs (DMDs) that include, natalizumab, interferon $\beta-1 \mathrm{a}$, interferon $\beta-1 \mathrm{~b}$, and teriflunomide were also recorded.

\section{Comorbidity}

Comorbidities in this study included the following: coronary artery, peripheral vascular, chronic pulmonary, cerebrovascular, peptic ulcer, rheumatologic, liver, and renal 
diseases. Other comorbidities included were diabetes mellitus, hemiplegia or paraplegia, malignancy, metastatic solid tumor, congestive heart failure, myocardial infarction, acquired immune deficiency syndrome/human immunodeficiency virus, infectious mononucleosis, hypertension, hyperlipidemia, lower leg fracture or surgery, systemic lupus erythematosus, rheumatoid arthritis, deficiency anemias, fluid or electrolyte disorders, smoking habit, and obesity. The reasons for the inclusion of these comorbidities in this analysis were that they are either clinical risk factors for MS, or have been suspected of being associated with development of MS. ${ }^{22,52-56}$ Table S1 lists all the ICD-9-CM codes for these comorbidities.

\section{Outcome Measures}

Psychiatric, or mental disorders, are defined as clinically significant behavioral or psychological syndromes, which are associated with present distress, disability, or an increased risk of suffering death, pain, or disability, and subsequent behavioral, psychological, or biological dysfunctions. $^{57,58}$ The included patients were all followed from the index date until the occurrence of any of the following events: onset of anxiety, depressive, bipolar, sleep, schizophrenia, schizophreniform disorder, other psychotic disorder, or substance-related (namely alcohol use or illicit drug use) disorders; withdrawal from the NHI program; or the end of 2015. All of the ICD-9-CM codes for the outcomes are listed in Table S1. In this study, we have separated these diagnoses by the first identified ICD codes in the subjects in these two cohorts.

\section{Statistical Analysis}

SPSS for Windows, version 22.0 (IBM Corp., Armonk, NY, USA) was applied in this study to execute all statistical analyses. The distribution of categorical variables was assessed using the $\chi^{2}$ test; in addition, that of continuous variables was determined by applying a $t$ test, with the Fisher exact test. On the basis of the model presented by Fine and Gray, this study executed a survival analysis to compare estimated hazards for patients with diseases that had a potential outcome of death, such as MS, with those for the controls. ${ }^{59}$ To perform this analysis, the SPSS value-added module, including competing risks survival analysis, was applied (https://www.asia-analytics.com.tw/ en/product/p-asia-analytics-2.jsp).Accordingly, we could employ the competing risk analysis approach put forward by Fine and Gray to identify the risk of psychiatric disorders (competing with death) in patients with MS. ${ }^{60}$ The results that were derived from the mentioned analysis are presented herein as hazard ratios (HRs) and their corresponding 95\% confidence intervals (CIs). We compared the control and study groups with respect to the risk of psychiatric disorders by executing the Kaplan-Meier method in conjunction with a Log rank test. A two-tailed $p$ value of $<0.05$ was deemed in this study as denoting statistical significance.

\section{Results}

\section{Sample Characteristics}

As indicated in Table 1, 1:3 matching was performed on the enrolled patients (1066 patients with MS and 3198 controls without MS) with respect to index year, sex, and age. There were statistically significant differences in hemiplegia or paraplegia, rheumatologic disease, liver disease, hyperlipidemia, lower leg fracture or surgery, systemic lupus erythematosus, deficiency anemias, and fluid and electrolyte disorders between the MS and control groups. The MS group tended to have a higher percentage of patients living in Northern or Eastern Taiwan, residing in areas with urbanization levels of 1 and 2, and seeking medical care from a medical center.

\section{Cumulative Risk of Psychiatric Disorders as Assessed Using the Kaplan-Meier Model}

Of the MS patients, 531 (4622.86 per $10^{5}$ person years) were determined to develop psychiatric disorders; by contrast, whereas 891 of the 3198 individuals in the control group $\left(2,85.31\right.$ per $10^{5}$ person years) were determined to develop psychiatric disorders. This difference reached statistical significance, as determined through the execution of Kaplan-Meier survival analysis (log rank, $p<0.001$, Figure 2).

\section{HR for Psychiatric Disorders in MS Group}

Table 2 presents the results derived from the analysis executed using the competing risk model. As revealed by the table, the MS group was determined to exhibit a higher likelihood of developing psychiatric disorders when compared with the control group (crude HR: 4.407; 95\% CI $=3.918-5.087, p<0.001)$. Moreover, the results indicated that after sex, monthly income, urbanization level, geographic region, comorbidities, and age were adjusted for, the adjusted HR was 5.044 
Table I Characteristics of Study at the Baseline

\begin{tabular}{|c|c|c|c|c|c|}
\hline \multirow[t]{2}{*}{ Variables } & \multicolumn{2}{|c|}{ MS Cohort } & \multicolumn{2}{|c|}{ Controls } & \multirow[t]{2}{*}{$P$} \\
\hline & $\mathbf{n}$ & $\%$ & $\mathbf{n}$ & $\%$ & \\
\hline Total & 1066 & 25.00 & 3198 & 75.00 & \\
\hline Sex & & & & & 0.999 \\
\hline Male & 210 & 19.70 & 630 & 19.70 & \\
\hline Female & 856 & 80.30 & 2568 & 80.30 & \\
\hline Age (years) & \multicolumn{2}{|c|}{$41.20 \pm 13.17$} & \multicolumn{2}{|c|}{$40.93 \pm 14.78$} & 0.596 \\
\hline Age group (years) & & & & & 0.999 \\
\hline $20-49$ & 788 & 73.92 & 2364 & 73.92 & \\
\hline $50-64$ & 224 & 21.01 & 672 & 21.01 & \\
\hline$\geqq 65$ & 54 & 5.07 & 162 & 5.07 & \\
\hline Marital status & & & & & 0.868 \\
\hline Single & 812 & 76.17 & 2428 & 75.92 & \\
\hline Married & 254 & 23.83 & 770 & 24.08 & \\
\hline Education (years) & & & & & 0.832 \\
\hline$<12$ & 500 & 46.90 & 1512 & 47.28 & \\
\hline$\geqq 12$ & 566 & 53.10 & 1686 & 52.72 & \\
\hline Insurance premium (NT\$) & & & & & 0.996 \\
\hline$<18,000$ & 861 & 80.77 & 2579 & 80.64 & \\
\hline $18,000-34,999$ & 139 & 13.04 & 420 & 13.13 & \\
\hline$\geqq 35,000$ & 66 & 6.19 & 199 & 6.22 & \\
\hline \multicolumn{6}{|l|}{ Comorbidities } \\
\hline Myocardial infarction & 3 & 0.28 & 10 & 0.31 & 0.873 \\
\hline Congestive heart failure & 1 & 0.09 & 18 & 0.56 & 0.046 \\
\hline Peripheral vascular disease & 0 & 0 & 0 & 0 & - \\
\hline Cerebrovascular disease & 28 & 2.63 & 70 & 2.19 & 0.409 \\
\hline Hemiplegia or paraplegia & 41 & 3.85 & 12 & 0.38 & $<0.001$ \\
\hline Chronic pulmonary disease & 14 & 1.31 & 65 & 2.03 & 0.132 \\
\hline Rheumatologic disease & 23 & 2.16 & 24 & 0.75 & $<0.001$ \\
\hline Peptic ulcer disease & 31 & 2.91 & 124 & 3.88 & 0.143 \\
\hline Diabetes & 57 & 5.35 & 167 & 5.22 & 0.874 \\
\hline Renal disease & 5 & 0.47 & 16 & 0.50 & 0.899 \\
\hline Malignancy & 60 & 5.63 & 232 & 7.25 & 0.069 \\
\hline Metastatic solid tumor & 6 & 0.56 & 32 & 1.00 & 0.188 \\
\hline Liver disease & 14 & 1.31 & 158 & 4.94 & $<0.001$ \\
\hline AIDS/HIV & 1 & 0.09 & 0 & 0 & 0.083 \\
\hline Infectious mononucleosis & 0 & 0 & 0 & 0 & - \\
\hline Hypertension & 74 & 6.94 & 190 & 5.94 & 0.240 \\
\hline Hyperlipidemia & 42 & 3.94 & 13 & 0.41 & $<0.001$ \\
\hline Lower leg fracture or surgery & 1 & 0.09 & 65 & 2.03 & $<0.001$ \\
\hline Coronary artery disease & 26 & 2.44 & 81 & 2.53 & 0.865 \\
\hline Systemic lupus erythematosus & 15 & 1.41 & 9 & 0.28 & $<0.001$ \\
\hline Rheumatoid arthritis & 4 & 0.38 & 8 & 0.25 & 0.504 \\
\hline Deficiency anemias & 10 & 0.94 & 11 & 0.34 & 0.016 \\
\hline Fluid and electrolyte disorders & 25 & 2.35 & 12 & 0.38 & $<0.001$ \\
\hline Smoking & 0 & 0 & 0 & 0 & - \\
\hline Obesity & 1 & 0.09 & 0 & 0 & 0.083 \\
\hline
\end{tabular}


Table I (Continued).

\begin{tabular}{|c|c|c|c|c|c|}
\hline \multirow{3}{*}{$\begin{array}{l}\text { Variables } \\
\text { Annual medical visits }\end{array}$} & \multicolumn{2}{|c|}{ MS Cohort } & \multicolumn{2}{|c|}{ Controls } & \multirow[t]{2}{*}{$P$} \\
\hline & $\mathbf{n}$ & $\%$ & $\mathbf{n}$ & $\%$ & \\
\hline & \multicolumn{2}{|c|}{$9.42 \pm 10.12$} & \multicolumn{2}{|c|}{$10.01 \pm 11.25$} & 0.129 \\
\hline Location & & & & & $<0.001$ \\
\hline Northern Taiwan & 549 & 51.50 & 1364 & 42.65 & \\
\hline Middle Taiwan & 206 & 19.32 & 845 & 26.42 & \\
\hline Southern Taiwan & 257 & 24.11 & 837 & 26.17 & \\
\hline Eastern Taiwan & 54 & 5.07 & 138 & 4.32 & \\
\hline Outlets islands & 0 & 0.00 & 14 & 0.44 & \\
\hline Urbanization level & & & & & $<0.001$ \\
\hline I (The highest) & 542 & 50.84 & 1233 & 38.56 & \\
\hline 2 & 448 & 42.03 & 1310 & 40.96 & \\
\hline 3 & 27 & 2.53 & 262 & 8.19 & \\
\hline 4 (The lowest) & 49 & 4.60 & 393 & 12.29 & \\
\hline Level of care & & & & & $<0.001$ \\
\hline Medical center & 786 & 73.73 & 1014 & 31.71 & \\
\hline Regional hospital & 239 & 22.42 & 1132 & 35.40 & \\
\hline Local hospital & 41 & 3.85 & 1052 & 32.90 & \\
\hline
\end{tabular}

Note: $P$ : Chi-square/Fisher exact test on category variables and $t$-test on continue variables.

Abbreviations: MS, multiple sclerosis; NT\$, New Taiwan Dollars; AIDS/HIV, acquired immunodeficiency syndrome/human immunodeficiency virus infection.

(95\% confidence interval $=4.448-5.870, p<0.001)$. The results suggested that patients in the MS group who had CCI scores of 2 to 4 and who received medical care from a regional hospital or medical center exhibited a higher risk of psychiatric disorders. Male patients exhibited a lower risk.

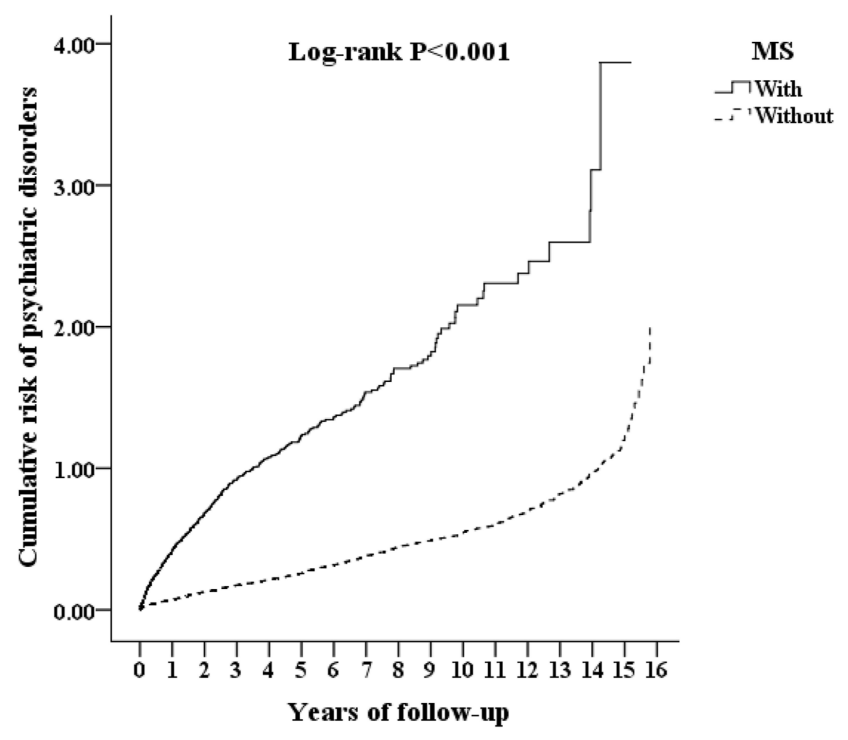

Figure 2 Kaplan-Meier for cumulative incidence of psychiatric disorders aged 20 and over stratified by multiple sclerosis (MS) with Log rank test.

\section{Sensitivity Analysis and Types of Psychiatric Disorders After MS Diagnosis}

As presented in Table 3, the MS group had associations with psychiatric disorders such as depression, anxiety, bipolar disorder, sleep disorders, schizophrenia, schizophreniform disorder, and other psychotic disorder (adjusted HR: 12.464, 4.650, 6.987, 9.103, 2.552, 2.600, 2.441 , and 2.574, respectively; all $p<0.001$ ) but not with substance-related disorders. The results of the sensitivity analysis of patients with MS (Table 3) also indicated their association with an increased risk of psychiatric disorders such as depression, anxiety, bipolar disorder, sleep disorders, schizophrenia, schizophreniform disorder, and other psychotic disorder, even after the exclusion of patients who had been diagnosed these psychiatric disorders during the first 1 year. However, after exclusion of patients with these psychiatric disorders during the first 5 years, MS was not associated with schizophrenia and schizophreniform disorder.

\section{Medications for MS and the Risk of Psychiatric Disorders}

We also analyzed the association between medications, or DMDs, for MS (Figure 3), and the portion of days covered (PDC) was $1 \%-50 \%$ (Table 4). In general, the results 


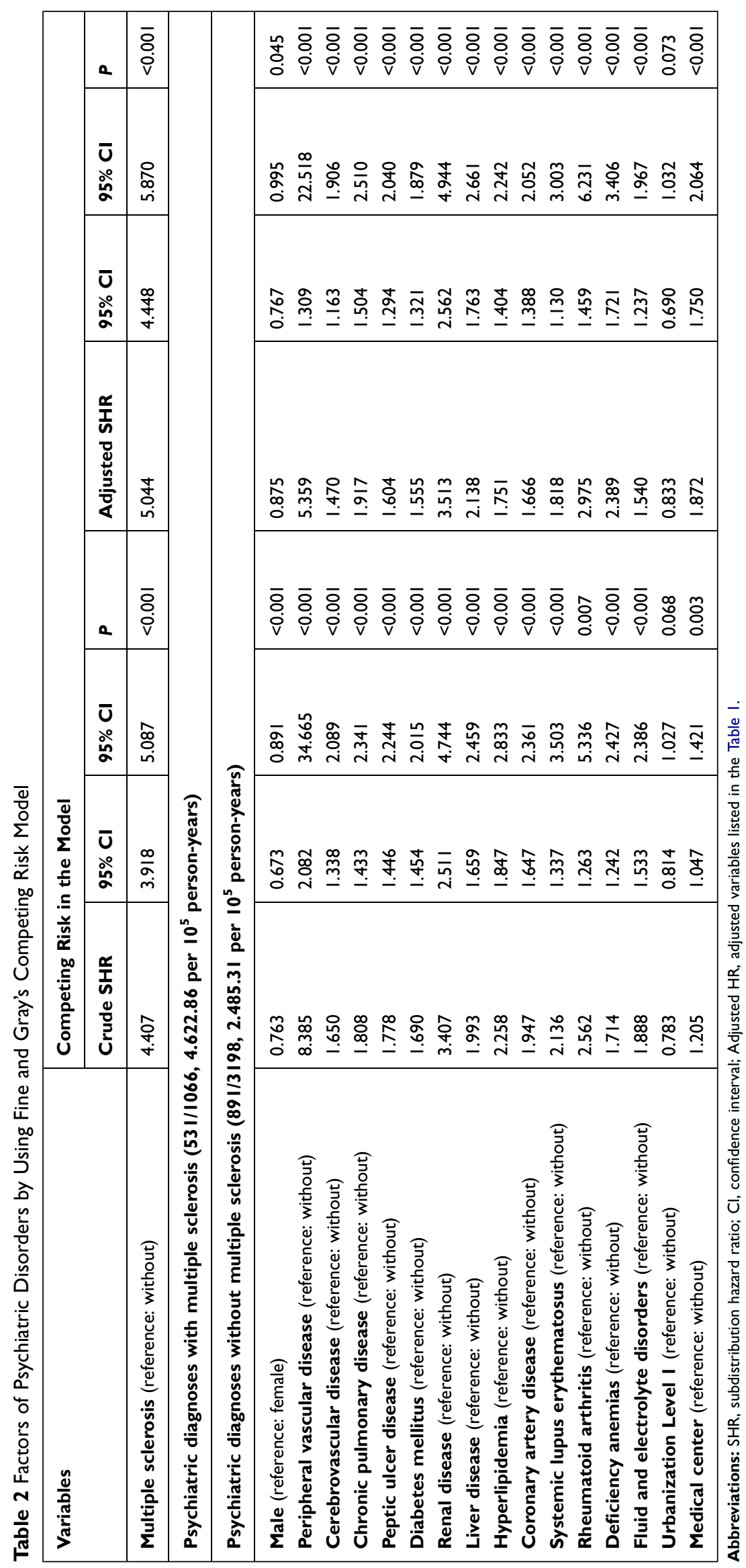




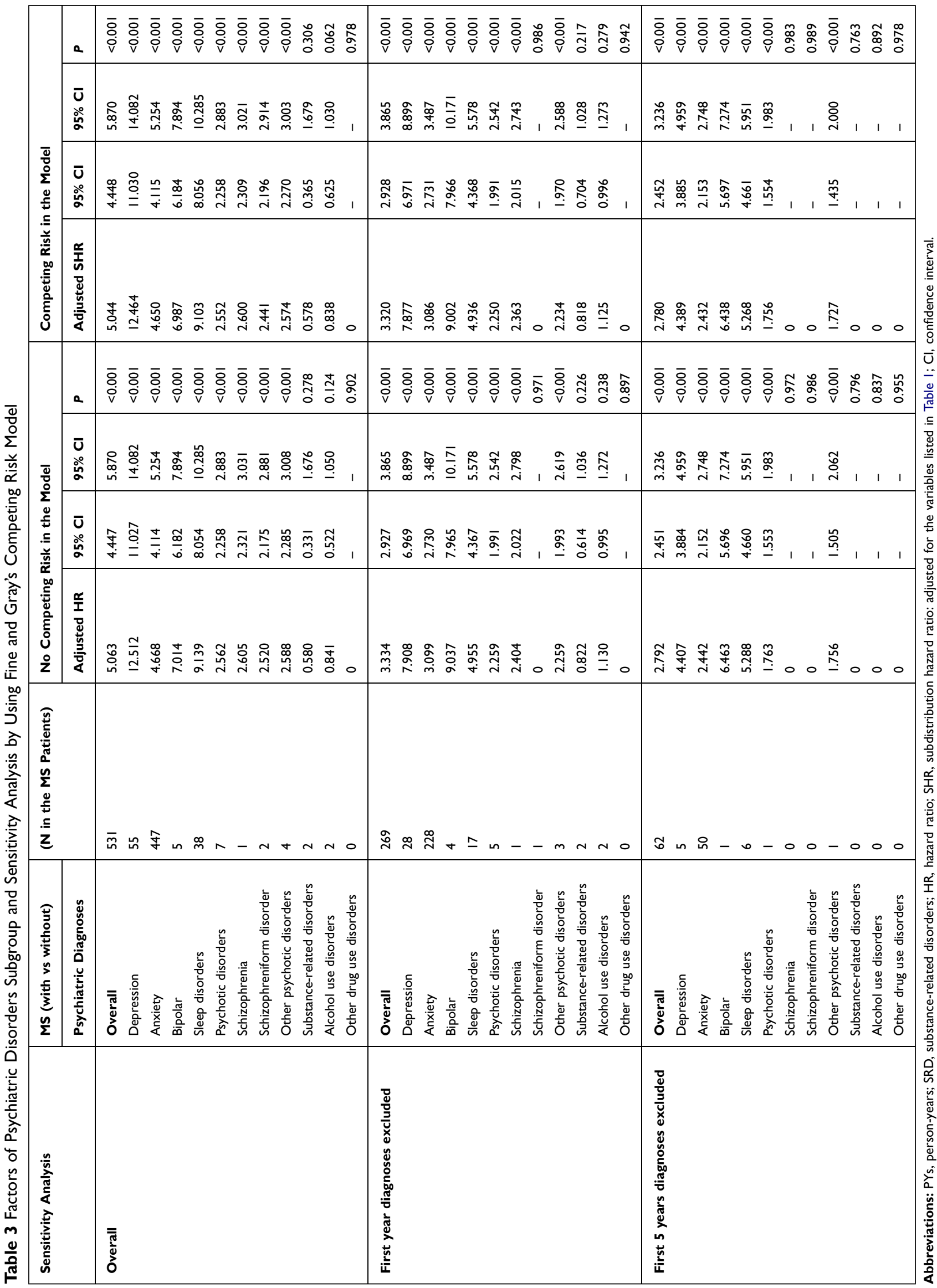






Figure 3 The flowchart of study sample selection from National Health Insurance Research Database in Taiwan.

revealed no association between the use of these medications and the overall risk of psychiatric disorders (Figure 4 and Table 5). However, in the present study, the use of glatiramer acetate, interferon- $\beta$ - $1 \mathrm{a}$, interferon- $\beta-1 \mathrm{~b}$, natalizumab, teriflunomide was determined to exhibit an association with a reduction in the anxiety risk. The use of glatiramer acetate, interferon- $\beta$ - $1 \mathrm{a}$, interferon- $\beta$ - $1 \mathrm{~b}$, teriflunomide was also noted to exhibit an association with a reduction in the risk of depression.

\section{Discussion}

\section{Association Between MS, DMDs, and the Risk of Psychiatric Disorders}

Our derived results suggest that MS is associated with an elevated risk of psychiatric disorders among adults. We also noted that after covariates were adjusted for, the risk of psychiatric disorders is nearly five-fold greater among adults with MS relative to those without MS. The results of Kaplan-Meier analysis indicated that the patients with MS in this study had a significantly higher rate of survival for 15 years without psychiatric disorders than did adults without MS.

In addition, we found that the DMD compliance among patients with MS was lower than 50\% because the PDC was $1 \%-50 \%$. Although some studies conducted in other countries have addressed this matter, the present study is also the first to report findings regarding DMD adherence or compliance in Taiwan. ${ }^{61,62}$ Furthermore, the use of such DMDs was noted to exhibit an association with a reduction in the anxiety and depression risks.

\section{Comparison of This Study with Previous Literature}

A previously executed systematic review ranked psychiatric disorders as follows with respect to their prevalence: depression (23.7\%), anxiety (21.9\%), alcohol abuse $(14.8 \%)$, bipolar disorder $(5.83 \%)$, psychosis $(4.3 \%)$, and substance abuse $(2.5 \%) .^{20}$ Compared with the populationbased studies on individual disorders, such as anxiety disorders, ${ }^{21,63,64}$ depression, ${ }^{64,65}$ and psychosis, ${ }^{24}$ identified 
Table 4 Distribution of Disease-Modifying Medications for Multiple Sclerosis

\begin{tabular}{|c|c|c|c|c|c|c|}
\hline Variables & $\mathbf{n}$ & $\%$ & Events & Events \% & PYs & Rate (per $10^{5}$ PYs) \\
\hline Total & 1066 & & 531 & 49.81 & $1 \mathrm{I}, 483.42$ & 4624.06 \\
\hline \multicolumn{7}{|l|}{ Drugs } \\
\hline Without & 882 & 82.74 & 456 & 51.70 & 9075.13 & 5024.72 \\
\hline With & 184 & 17.26 & 75 & 40.76 & 2408.29 & 3114.24 \\
\hline \multicolumn{7}{|l|}{ Fingolimod } \\
\hline Without & 931 & 87.34 & 471 & 50.59 & 9739.24 & 4836.11 \\
\hline PDC I-50\% & 135 & 12.66 & 60 & 44.44 & 1744.18 & 3440.01 \\
\hline PDC $51-100 \%$ & 0 & 0 & 0 & - & 0 & - \\
\hline MPR I-50\% & 89 & 8.35 & 55 & 61.80 & 1216.99 & 4519.35 \\
\hline MPR $5 \mathrm{I}-100 \%$ & 46 & 4.32 & 5 & 10.87 & 527.19 & 948.42 \\
\hline \multicolumn{7}{|c|}{ Glatiramer acetate } \\
\hline Without & 929 & 87.15 & 474 & 51.02 & 9745.85 & 4863.61 \\
\hline PDC I-50\% & 137 & 12.85 & 57 & 41.61 & 1737.57 & 3280.44 \\
\hline PDC $51-100 \%$ & 0 & 0 & 0 & - & 0 & - \\
\hline MPR I-50\% & 97 & 9.10 & 51 & 52.58 & $130 \mid .82$ & 3917.59 \\
\hline MPR $5 \mathrm{I}-100 \%$ & 40 & 3.75 & 6 & 15.00 & 435.75 & 1376.92 \\
\hline \multicolumn{7}{|l|}{ Interferon- $\beta-\mid \mathrm{a}$} \\
\hline Without & 910 & 85.37 & 484 & 53.19 & 9645.12 & 5018.08 \\
\hline PDC I-50\% & 151 & 14.17 & 45 & 29.80 & 1533.25 & 2934.94 \\
\hline PDC $51-100 \%$ & 5 & 0.47 & 2 & 40.00 & 305.05 & 655.63 \\
\hline MPR I-50\% & 102 & 9.57 & 44 & 43.14 & 1425.25 & 3087.18 \\
\hline MPR $5 \mathrm{I}-100 \%$ & 54 & 5.07 & 3 & 5.56 & 413.05 & 726.30 \\
\hline \multicolumn{7}{|l|}{ Interferon- $\beta$ - Ib } \\
\hline Without & 918 & 86.12 & 501 & 54.58 & 9575.98 & 5231.84 \\
\hline PDC I-50\% & 142 & 13.32 & 29 & 20.42 & 1513.12 & 1916.57 \\
\hline PDC $51-100 \%$ & 6 & 0.56 & I & 16.67 & 394.32 & 253.60 \\
\hline MPR I-50\% & 101 & 9.47 & 28 & 27.72 & 1499.76 & 1866.97 \\
\hline MPR 5I-100\% & 47 & $4.4 I$ & 2 & 4.26 & 407.68 & 490.58 \\
\hline \multicolumn{7}{|l|}{ Natalizumab } \\
\hline Without & 924 & 86.68 & 510 & 55.19 & 9480.25 & 5379.60 \\
\hline PDC I-50\% & $|3|$ & 12.29 & 20 & 15.27 & 1813.12 & II 03.07 \\
\hline PDC $51-100 \%$ & II & 1.03 & 1 & 9.09 & 190.05 & 526.18 \\
\hline MPR I-50\% & 94 & 8.82 & 20 & 21.28 & 1806.27 & 1107.25 \\
\hline MPR $5 \mathrm{I}-100 \%$ & 48 & 4.50 & I & 2.08 & 196.90 & 507.87 \\
\hline \multicolumn{7}{|l|}{ Teriflunomide } \\
\hline Without & 928 & 87.05 & 498 & 53.66 & 9698.25 & 5134.95 \\
\hline PDC I-50\% & 130 & 12.20 & 33 & 25.38 & 1327.42 & 2486.03 \\
\hline PDC $51-100 \%$ & 8 & 0.75 & 0 & 0 & 457.75 & 0 \\
\hline MPR I-50\% & 107 & 10.04 & 29 & 27.10 & 1301.56 & 2228.10 \\
\hline MPR $5 I-100 \%$ & 31 & 2.91 & 4 & 12.90 & 483.61 & 827.11 \\
\hline
\end{tabular}

Abbreviations: PYs, Person-year; PDC, portion of days covered; MPR, medication possession ratio.

during our systematic review, our study is the first to use a large and nationwide administrative data set for several major psychiatric disorders.

Furthermore, the treatment prevalence rates of the psychiatric disorders among the patients in our study were
$83.9 \%$ for anxiety disorders, $10.3 \%$ for depression, and $7.1 \%$ for sleep disorders; by contrast, the prevalence rates of psychotic disorders, bipolar disorder, and substancerelated disorders were lower than $2 \%$ in the reviewed studies. ${ }^{14}$ We speculate that this difference may be related 


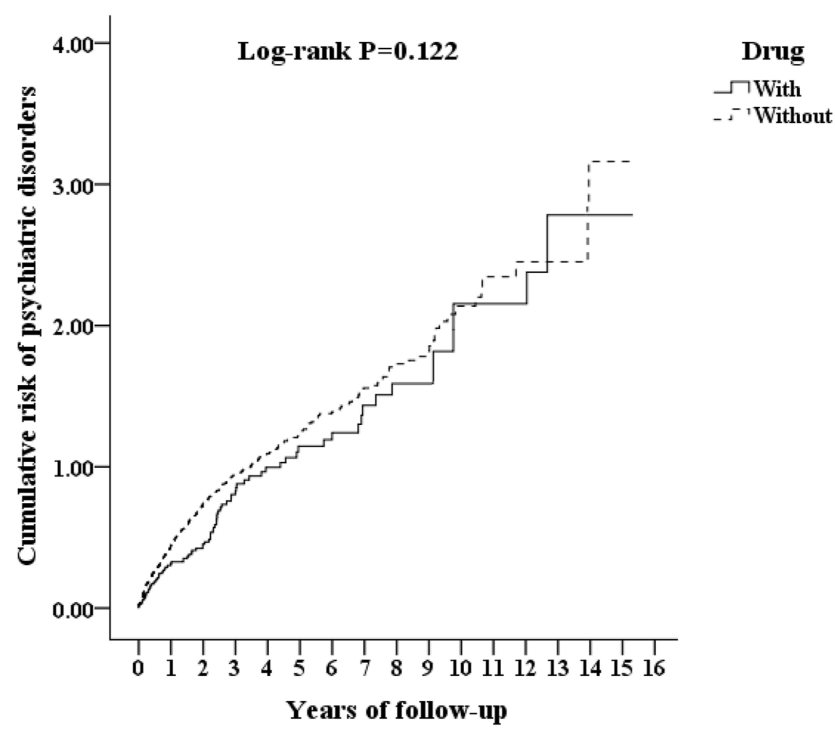

Figure 4 Kaplan-Meier for cumulative risk of psychiatric disorders among MS patients aged 20 and over stratified by treatment with Log rank test.

to the different follow-up period and different enrollment criteria for psychiatric disorders in this study. This study enrolled only patients who had made three visits in a year for treating their diagnosed psychiatric disorder. Furthermore, our study involved a longer follow-up duration for the psychiatric disorders in the patients with MS following their hospital stay; this longer duration constitutes a strength of the study. However, the reasons for this difference require further investigation.

Confavreux and Compston reported that the prognosis for men with MS is typically worse than that for women, and disability appears to have more of an impact on the quality of life in men. ${ }^{66}$ Another study also found that the very early stages of MS are accompanied by disturbances in psychological well-being and mild cognitive dysfunction, particularly in male patients. ${ }^{67}$ However, in the present study, male patients with MS were determined to have a lower risk of psychiatric disorders (adjusted HR $=0.792$ [95\% CI $=0.651-0.953, p=0.006])$. One possible explanation for this finding is that the psychological support provided by the health professionals might be insufficient for men, ${ }^{68}$ thus reducing the rates of early detection and early referrals and consequently lowering the psychiatric diagnostic rates in the NHIRD. Furthermore, previous studies have found that the male patients generally tended to be reluctant to seek help from psychiatric services. ${ }^{69-71}$ This might also contribute to the apparently lower risk of psychiatric disorders in the male patients with MS. In addition, we determined higher insurance premiums to have an association with a higher MS risk. The reasons underlying this association are not known. We speculate that subjects with higher insurance premiums, suggesting that they have higher income, might have higher accessibility to health care systems. Nonetheless, the reasons for this lower risk are still unknown and need to be researched further with more detail.

In contrast to other studies, although this study found an association between MS and an increased risk of anxiety, depression, psychotic disorders, sleep disorders, and bipolar disorder, no association was noted between MS and substance-related disorders. ${ }^{72,73}$ Low baseline rates of alcohol or drug use disorders in Taiwan might be one explanation for this discrepancy. ${ }^{74}$

In this claims data set-based study, we identified patients with MS on the basis of a discharge diagnosis of MS, as confirmed by CIC approval. The number of patients with MS who did not have CICs was difficult to estimate because all studies on the prevalence of MS in Taiwan have analyzed data from the NHIRD. ${ }^{15-17,75}$ However, we speculate that most of the patients with MS were issued CICs because NHI regulations exempt them from copayment for MS-related medical care. Furthermore, most researchers using data from the NHIRD have used CIC status to confirm MS diagnosis. $^{24,25,46,56,76-81}$ Nonetheless, a community-based study in Taiwan is necessary to determine the proportion of patients with MS who do not have CICs. In addition, NHI regulations mandate that a period of three to seven days elapse after confirmation of diagnosis by a physician before CICs can be issued so that medical charts can be reviewed by NHIA-appointed specialists to verify the validity of certificates issued for CIC-qualifiable diseases, including MS. ${ }^{82}$ However, determining the mean number of days between diagnosis of MS and CIC registration remains difficult.

\section{Potential Mechanisms Underlying the Elevated Risk of Psychiatric Disorders Among Patients with MS}

Studies have reported associations of multiple factors, such as brain pathology, genetics, immunological changes, psychosocial influences, and dysregulation of the hypothalamic-pituitary-adrenal axis, with anxiety disorders and depression. ${ }^{83}$ One study reported that MS, depressive disorder, bipolar disorder, and schizophrenia may share the mechanism of downregulating oligodendrocyte genes. ${ }^{84}$ However, the mechanisms that underlie the MS-psychiatric disorder risk association require further investigation. 







\begin{tabular}{|c|c|c|c|}
\hline $\begin{array}{l}n \\
\hat{\sigma} \\
o\end{array}$ &  & 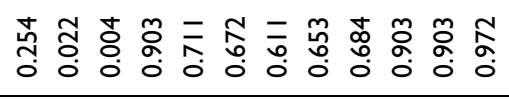 & 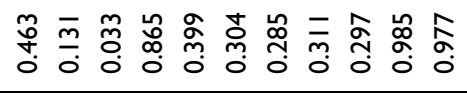 \\
\hline 1 &  & 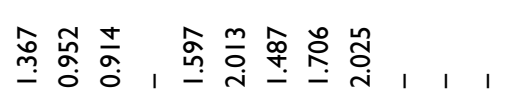 & 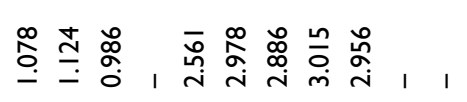 \\
\hline 1 & 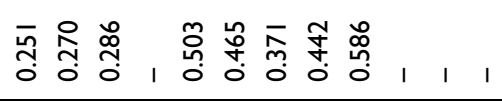 & 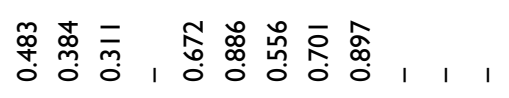 & 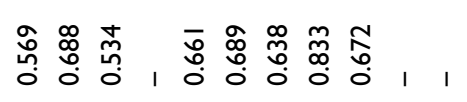 \\
\hline 0 & 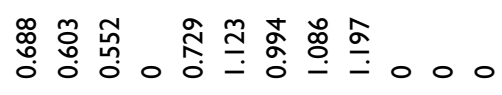 &  & 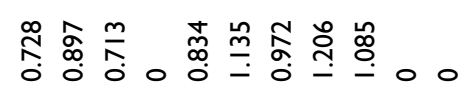 \\
\hline 客 & 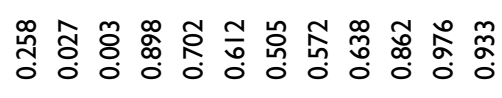 & సָ̃ & 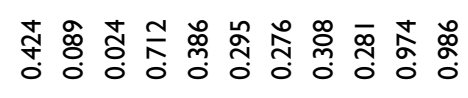 \\
\hline 1 & 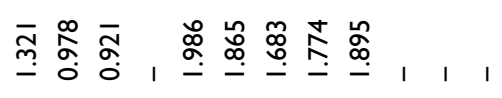 & 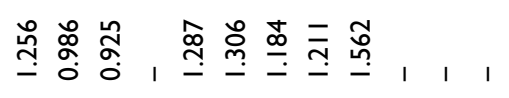 & 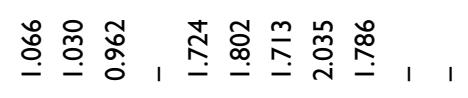 \\
\hline 1 & స̦ & 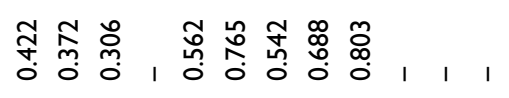 & 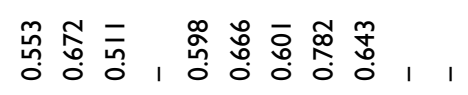 \\
\hline 0 & 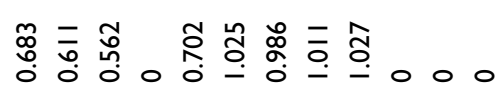 & 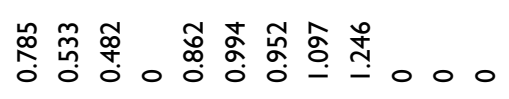 & 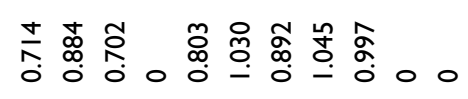 \\
\hline 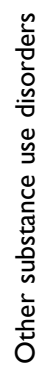 & 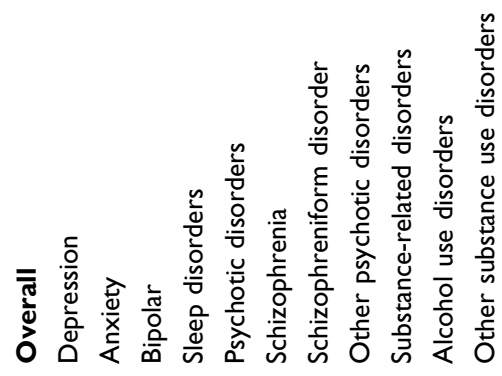 & 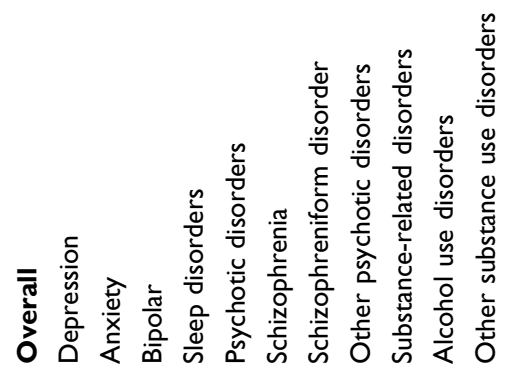 & 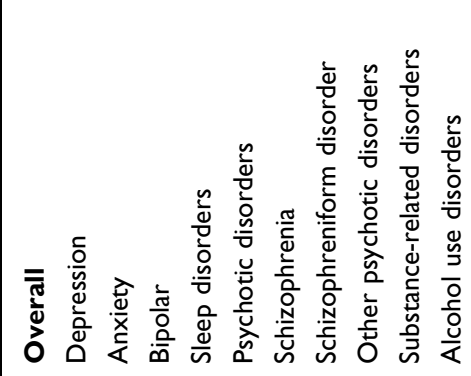 \\
\hline & 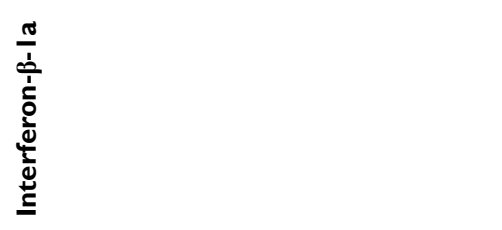 &  & 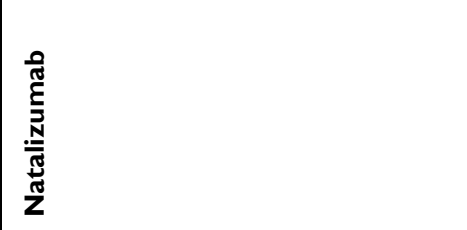 \\
\hline
\end{tabular}






\section{Study Strengths}

This research has certain strengths. First, we employed Taiwan's NHIRD, a very important resource covering a nationwide population. Second, other studies have verified the diagnostic validity of several neuropsychiatric disorders included in the NHIRD, including Tourette syndrome,${ }^{85}$ stroke, ${ }^{86-89}$ sleep apnea,${ }^{90}$ and major depressive disorder. ${ }^{91}$ Moreover, as mentioned, in-hospital licensed medical record technicians and NHI administrators would have verified the diagnoses in the claims data set. $^{27,44}$ Third, the consistency between the NHIRD and Taiwan's National Health Survey with respect to various diagnoses, ${ }^{92}$ medication usages, ${ }^{92}$ and health system utilizations ${ }^{92,93}$ has been verified by research. Fourth, a benefit of the Fine and Gray model is that it includes real mortality data for investigating how MS influences the risk of psychiatric disorders. ${ }^{94,95}$ Therefore, this study was conducted using a large, nationwide, and reliable database to determine the association between MS and psychiatric morbidities in an Asian country.

\section{Limitations of This Study}

This research has a few limitations that should be considered. First, because not all pieces of data are recorded in the NHIRD, we could not evaluate the influence of family history, neurological severity, types, laboratory parameters, findings from additional examinations (eg, neuroimaging), or use of rehabilitation services. ${ }^{80}$ Therefore, the lack of data regarding the clinical and radiological course and treatment of the disease is a limitation of this nationwide study with a large sample size, similar to the case for other studies that have used the NHIRD to investigate MS. ${ }^{24,56,76,77}$ Second, data regarding certain factors, such as those related to environmental conditions, psychosocial characteristics, and genetics, were not part of the data set. Because the data we applied in our study spanned 15 years and encompassed the entirety of the hospitals in Taiwan and more than $99 \%$ of Taiwan's population, they are likely to be representative and valid.

\section{Conclusions}

The present study provides evidence demonstrating that MS is associated with an increase in the risk of psychiatric disorders, such as anxiety disorders, depression, and bipolar disorder. This finding can remind clinicians regarding the importance of considering the risk of psychiatric disorders subsequently arising among patients with MS. For example, clinicians could 
use the mental health screening instruments to identify the patients at risk early on. Additional studies are warranted to explore the association of MS with depression and anxiety disorders in a larger community sample by setting a longer follow-up duration and considering lifestyle, family history, psychosocial stressors, and MS severity.

\section{Data Sharing Statement}

Data are available from the NHIRD published by the Taiwan NHI administration. Because of legal restrictions imposed by the government of Taiwan concerning the "Personal Information Protection Act," data cannot be made publicly available. Requests for data can be sent as a formal proposal to the NHIRD (http://www.mohw.gov. tw/cht/DOS/DM1.aspx?f list no=812).

\section{Acknowledgments}

This work was supported by the Medical Affairs Bureau, the Ministry of Defense of Taiwan (MND-MAB-107-084 and MND-MAB-110-087), and the Tri-Service General Hospital Research Foundation (TSGH-C108-003, TSGHC108-027, TSGH-C108-151, TSGH-E-110240, TSGH-B-109-010, and TSGH-B-110012). These funding agencies did not influence the study design, data collection and analysis, decision to publish, or preparation of the manuscript. We also appreciate Taiwan's Health and Welfare Data Science Center and the Ministry of Health and Welfare (HWDC, MOHW) for providing the National Health Research Database.

\section{Author Contributions}

All authors made substantial contributions to the conception and design, acquisition of data, or analysis and interpretation of data; took part in drafting the article or revising it critically for important intellectual content; have approved of the final version of the manuscript for publication; and agree to be accountable for all aspects of the work.

\section{Disclosure}

The authors declare that the research was conducted in the absence of any commercial or financial relationships that could be construed as a potential conflict of interest.

\section{References}

1. Thompson AJ, Baranzini SE, Geurts J, Hemmer B, Ciccarelli O. Multiple sclerosis. Lancet. 2018;391(10130):1622-1636. doi:10.1016/ S0140-6736(18)30481-1
2. Moore F, Vickrey B, Fortin K, Lee L. Two multiple sclerosis qualityof-life measures: comparison in a national sample. Can J Neurol Sci. 2015;42(1):55-63. doi:10.1017/cjn.2014.128

3. Filippi M, Preziosa P, Rocca MA. Brain mapping in multiple sclerosis: lessons learned about the human brain. NeuroImage. 2017.

4. Marrie RA, Walld R, Bolton JM, et al. Increased incidence of psychiatric disorders in immune-mediated inflammatory disease. $J$ Psychosom Res. 2017;101:17-23. doi:10.1016/j.jpsychores.2017.07.015

5. Tzeng NS, Chang HA, Chung CH, et al. Risk of psychiatric disorders in Guillain-Barre syndrome: a nationwide, population-based, cohort study. J Neurol Sci. 2017;381:88-94. doi:10.1016/j.jns.2017.08.022

6. Tzeng NS, Chung CH, Liu FC, et al. Fibromyalgia and risk of dementia-A Nationwide, Population-Based, Cohort Study. Am J Med Sci. 2018;355(2):153-161. doi:10.1016/j.amjms.2017.09.002

7. Tzeng NS, Chang HA, Chung $\mathrm{CH}$, et al. Increased risk of psychiatric disorders in allergic diseases: a Nationwide, Population-Based, Cohort Study. Front Psychiatry. 2018;9:133. doi:10.3389/fpsyt.20 18.00133

8. Tzeng NS, Chung $\mathrm{CH}$, Yeh CB, et al. Are chronic periodontitis and gingivitis associated with dementia? A Nationwide, Retrospective, Matched-Cohort Study in Taiwan. Neuroepidemiology. 2016;47 (2):82-93. doi:10.1159/000449166

9. Chen CK, Wu YT, Chang YC. Association between chronic periodontitis and the risk of Alzheimer's disease: a retrospective, population-based, matched-cohort study. Alzheimer's Res Ther. 2017;9 (1):56. doi:10.1186/s13195-017-0282-6

10. Lee YL, Hu HY, Huang LY, Chou P, Chu D. Periodontal disease associated with higher risk of dementia: population-Based Cohort Study in Taiwan. J Am Geriatr Soc. 2017;65(9):1975-1980. doi:10. 1111/jgs. 14944

11. Lee YT, Lee HC, Hu CJ, et al. Periodontitis as a Modifiable risk factor for dementia: a Nationwide Population-Based Cohort Study. $J$ Am Geriatr Soc. 2017;65(2):301-305. doi:10.1111/jgs.14449

12. Sgambato D, Miranda A, Ranaldo R, Federico A, Romano M. The role of stress in inflammatory bowel diseases. Curr Pharm Des. 2017;23(27). doi:10.2174/1381612823666170228123357

13. Marrie RA, Reingold S, Cohen J, et al. The incidence and prevalence of psychiatric disorders in multiple sclerosis: a systematic review. Mult Scler J. 2015;21(3):305-317. doi:10.1177/1352458514564487

14. Marrie RA, Reider N, Cohen J, et al. A systematic review of the incidence and prevalence of sleep disorders and seizure disorders in multiple sclerosis. Mult Scler J. 2015;21(3):342-349. doi:10.1177/ 1352458514564486

15. Tsai CP, Yuan CL, Yu HY, Chen C, Guo YC, Shan DE. Multiple sclerosis in Taiwan. J Chin Med Assoc. 2004;67(10):500-505.

16. Lai CH, Tseng HF. Population-based epidemiological study of neurological diseases in Taiwan: I. Creutzfeldt-Jakob disease and multiple sclerosis. Neuroepidemiology. 2009;33(3):247-253. doi:10.1159/ 000229779

17. Cheong WL, Mohan D, Warren N, Reidpath DD. Multiple sclerosis in the Asia Pacific region: a systematic review of a neglected neurological disease. Front Neurol. 2018;9:432. doi:10.3389/fneur.2018. 00432

18. Wallin MT, Culpepper WJ, Campbell JD, et al. The prevalence of MS in the United States: A population-based estimate using health claims data. Neurology. 2019;92(10):e1029-e1040. doi:10.1212/WNL.000 0000000007035

19. Dilokthornsakul P, Valuck RJ, Nair KV, Corboy JR, Allen RR, Campbell JD. Multiple sclerosis prevalence in the United States commercially insured population. Neurology. 2016;86(11):10141021. doi:10.1212/WNL.0000000000002469

20. Marrie RA, Cohen J, Stuve O, et al. A systematic review of the incidence and prevalence of comorbidity in multiple sclerosis: overview. Mult Scler J. 2015;21(3):263-281. doi:10.1177/135245851 4564491 
21. Marrie RA, Fisk JD, Yu BN, et al. Mental comorbidity and multiple sclerosis: validating administrative data to support population-based surveillance. BMC Neurol. 2013;13:16. doi:10.1186/1471-2377-13-16

22. Marrie RA, Miller A, Sormani MP, et al. Recommendations for observational studies of comorbidity in multiple sclerosis. Neurology. 2016;86(15):1446-1453. doi:10.1212/WNL.0000000000 002474

23. Marrie RA, Walld R, Bolton JM, et al. Rising incidence of psychiatric disorders before diagnosis of immune-mediated inflammatory disease. Epidemiol Psychiatr Sci. 2017;1-10.

24. Kang JH, Chen YH, Lin HC. Comorbidities amongst patients with multiple sclerosis: a population-based controlled study. Eur J Neurol. 2010;17(9):1215-1219. doi:10.1111/j.1468-1331.2010.02971.x

25. Keller JJ, Liang YC, Lin HC. Association between multiple sclerosis and erectile dysfunction: a nationwide case-control study. J Sex Med. 2012;9(7):1753-1759. doi:10.1111/j.1743-6109.2012.02746.x

26. Ho Chan WS. Taiwan's healthcare report 2010. EPMA J. 2010;1 (4):563-585. doi:10.1007/s13167-010-0056-8

27. Hsieh C-Y, Su -C-C, Shao S-C, et al. Taiwan's National Health Insurance Research Database: past and future. Clin Epidemiol. 2019;11:349-358. doi:10.2147/CLEP.S196293

28. Chien WC, Chung CH, Lin FH, Chang HA, Kao YC, Tzeng NS. Is weight control surgery associated with increased risk of newly onset psychiatric disorders? A population-based, matched cohort study in Taiwan. J Med Sci. 2017;37(4):137-149. doi:10.4103/jmedsci. jmedsci_94_16

29. Kao LC, Chien WC, Chung $\mathrm{CH}$, et al. The newly diagnosed amnestic disorders and dementia: a Nationwide, Cohort Study in Taiwan. Taiwan J Psychiatry. 2018;32(1):18-28.

30. Yang $\mathrm{CC}$, Chien WC, Chung $\mathrm{CH}$, et al. No association between human immunodeficiency virus infections and dementia: a Nationwide Cohort Study In Taiwan. Neuropsychiatr Dis Treat. 2019;15:3155-3166. doi:10.2147/NDT.S225584

31. Chen TY, Huang $\mathrm{CH}$, Chung $\mathrm{CH}$, et al. Sex and age differences in the association between anxiety disorders and narcolepsy: A nationwide population-based case control study. J Affect Disord. 2020;264:130137. doi:10.1016/j.jad.2019.12.010

32. Lin YC, Chen TY, Chien WC, et al. Stimulants associated with reduced risk of hospitalization for motor vehicle accident injury in patients with obstructive sleep apnea-a nationwide cohort study. BMC Pulm Med. 2020;20(1). doi:10.1186/s12890-019-1041-1.

33. Liu YP, Chien WC, Chung CH, Chang HA, Kao YC, Tzeng NS. Are anticholinergic medications associated with increased risk of dementia and behavioral and psychological symptoms of dementia? A Nationwide 15-Year Follow-Up Cohort Study in Taiwan. Front Pharmacol. 2020;11.

34. Wan FJ, Chien WC, Chung CH, Yang YJ, Tzeng NS. Association between traumatic spinal cord injury and affective and other psychiatric disorders-A nationwide cohort study and effects of rehabilitation therapies. $J$ Affect Disord. 2020;265:381-388. doi:10.1016/j. jad.2020.01.063

35. Wang DS, Chung CH, Chang HA, et al. Association between child abuse exposure and the risk of psychiatric disorders: A nationwide cohort study in Taiwan. Child Abuse Negl. 2020;101:104362. doi:10.1016/j.chiabu.2020.104362

36. Lin $\mathrm{CH}$, Chien WC, Chung $\mathrm{CH}$, et al. Increased risk of dementia in patients with genital warts: A nationwide cohort study in Taiwan. $J$ Dermatol. 2020;47(5):503-511. doi:10.1111/1346-8138.15277

37. Yeh TC, Chien WC, Chung $\mathrm{CH}$, et al. Psychiatric disorders after traumatic brain injury: a Nationwide Population-Based Cohort Study and the effects of rehabilitation therapies. Arch Phys Med Rehabil. 2020;101(5):822-831. doi:10.1016/j.apmr.2019.12.005

38. Tzeng NS, Hsu YH, Ho SY, et al. Is schizophrenia associated with an increased risk of chronic kidney disease? A nationwide matchedcohort study. BMJ Open. 2015;5(1):e006777. doi:10.1136/bmjopen2014-006777
39. Chiou YE, Chien WC, Chung CH, et al. New users of herbal medicine containing aristolochic acids and the risk of dementia in the elderly: a Nationwide, Population-Based Study in Taiwan. Neuropsychiatr Dis Treat. 2020;16:1493-1504. doi:10.2147/NDT.S250659

40. Tzeng NS, Chien WC, Chun CH, Chang HA, Kao YC, Liu YP. Association between amphetamine-related disorders and dementia-a Nationwide Cohort Study in Taiwan. Ann Clin Transl Neurol. 2020;7 (8):1284-1295. doi:10.1002/acn3.51113

41. McDonald WI, Compston A, Edan G, et al. Recommended diagnostic criteria for multiple sclerosis: guidelines from the International Panel on the diagnosis of multiple sclerosis. Ann Neurol. 2001;50(1):121127. doi:10.1002/ana.1032

42. Polman CH, Reingold SC, Banwell B, et al. Diagnostic criteria for multiple sclerosis: 2010 revisions to the McDonald criteria. Ann Neurol. 2011;69(2):292-302. doi:10.1002/ana.22366

43. Thompson AJ, Banwell BL, Barkhof F, et al. Diagnosis of multiple sclerosis: 2017 revisions of the McDonald criteria. Lancet Neurol. 2018;17(2):162-173. doi:10.1016/S1474-4422(17)30470-2

44. Ministry of Justice. National health insurance reimbursement regulations; 2019. Available from: https://law.moj.gov.tw/LawClass/ LawAll.aspx?pcode=L0060035. Accessed December 18, 2019.

45. Tseng CC, Chang SJ, Tsai WC, et al. Increased incidence of multiple sclerosis in systemic sclerosis: A nationwide cohort study. Prev Med. 2016;84:6-11. doi:10.1016/j.ypmed.2015.12.006

46. Tseng CC, Chang SJ, Tsai WC, et al. Increased incidence of rheumatoid arthritis in multiple sclerosis: A nationwide cohort study. Medicine. 2016;95(26):e3999. doi:10.1097/MD.0000000000003999

47. National Health Insurance Adminitration. Data protection and regulations, in national health insurance research database. Available from: https://nhird.nhri.org.tw/en/Data_Protection.html. Accessed December, 9, 2020.

48. Chen YC, Yeh HY, Wu JC, Haschler I, Chen TJ, Wetter T. Taiwan's National Health Insurance Research Database: administrative health care database as study object in bibliometrics. Scientometrics. 2010;86(2):365-380. doi:10.1007/s11192-010-0289-2

49. Hsiao FY, Yang CL, Huang YT, Huang WF. Using Taiwan's national health insurance research databases for pharmacoepidemiology research. J Food Drug Anal. 2007;15:99-108.

50. Sung SF, Hsieh CY, Hu YH. Two decades of research using Taiwan's national health insurance claims data: bibliometric and text mining analysis on pubmed. J Med Internet Res. 2020;22(6):e18457. doi:10.2196/18457

51. National Cheng Kung University. Visualizing health data; 2020. Available from: https:/visualizinghealthdata.idv.tw/?route $=$ article/the sis. Accessed December 9, 2020.

52. Ramagopalan SV, Dobson R, Meier UC, Giovannoni G. Multiple sclerosis: risk factors, prodromes, and potential causal pathways. Lancet Neurol. 2010;9(7):727-739. doi:10.1016/S1474-4422(10) 70094-6

53. Young CA. Factors predisposing to the development of multiple sclerosis. Qjm. 2011;104(5):383-386. doi:10.1093/qjmed/hcr012

54. Wens I, Dalgas U, Stenager E, Eijnde BO. Risk factors related to cardiovascular diseases and the metabolic syndrome in multiple sclerosis - a systematic review. Mult Scler. 2013;19(12):1556-1564. doi:10.1177/1352458513504252

55. Belbasis L, Bellou V, Evangelou E, Ioannidis JP, Tzoulaki I. Environmental risk factors and multiple sclerosis: an umbrella review of systematic reviews and meta-analyses. Lancet Neurol. 2015;14 (3):263-273. doi:10.1016/S1474-4422(14)70267-4

56. Hou WH, Li CY, Chang HH, Sun Y, Tsai CC. A population-based cohort study suggests an increased risk of multiple sclerosis incidence in patients with type 2 diabetes mellitus. J Epidemiol. 2017;27 (5):235-241. doi:10.1016/j.je.2016.06.006

57. American Psychiatric Association. Diagnostic and Statistical Manual of Mental Disorders 4th Edition. 4 ed. USA: American Psychiatric Association; 1994. 
58. Stein DJ, Phillips KA, Bolton D, Fulford KW, Sadler JZ, Kendler KS What is a mental/psychiatric disorder? From DSM-IV to DSM-V. Psychol Med. 2010;40(11):1759-1765. doi:10.1017/S00332917099 92261

59. Fine JP, Gray RJ. A proportional hazards model for the subdistribution of a competing risk. J Am Stat Assoc. 1999;94(446):496-509. doi:10.1080/01621459.1999.10474144

60. Marzona I, Baviera M, Vannini T, et al. Risk of dementia and death in patients with atrial fibrillation: A competing risk analysis of a population-based cohort. Int J Cardiol. 2016;220:440-444. doi:10.1016/j. ijcard.2016.06.235

61. Degli Esposti L, Piccinni C, Sangiorgi D, et al. Changes in first-line injectable disease-modifying therapy for multiple sclerosis: predictors of non-adherence, switching, discontinuation, and interruption of drugs. Neurol Sci. 2017;38(4):589-594. doi:10.1007/s10072-016-2806-4

62. Duchovskiene N, Mickeviciene D, Jurkeviciene G, Dirziuviene B, Balnyte R. Factors associated with adherence to disease modifying therapy in multiple sclerosis: an observational survey from a referral center in Lithuania. Mult Scler Relat Disord. 2017;13:107-111. doi:10.1016/j.msard.2017.02.016

63. Poder K, Ghatavi K, Fisk JD, et al. Social anxiety in a multiple sclerosis clinic population. Mult Scler J. 2009;15(3):393-398. doi: $10.1177 / 1352458508099143$

64. Wood B, van der Mei IA, Ponsonby AL, et al. Prevalence and concurrence of anxiety, depression and fatigue over time in multiple sclerosis. Mult Scler J. 2013;19(2):217-224. doi:10.1177/13524 58512450351

65. Beiske AG, Svensson E, Sandanger I, et al. Depression and anxiety amongst multiple sclerosis patients. Eur J Neurol. 2008;15(3):239245. doi:10.1111/j.1468-1331.2007.02041.x

66. Confavreux C, Compston A. The natural history of multiple sclerosis. In: Compston A, editor. McAlpine's Multiple Sclerosis. 4th ed. London: Churchill Livingstone Elsevier; 2006:183-272.

67. Prokopova B, Hlavacova N, Vlcek M, et al. Early cognitive impairment along with decreased stress-induced BDNF in male and female patients with newly diagnosed multiple sclerosis. J Neuroimmunol. 2017;302:34-40. doi:10.1016/j.jneuroim.2016.11.007

68. Upton D, Taylor C. What are the support needs of men with multiple sclerosis, and are they being met? Int J MS Care. 2015;17(1):9-12. doi:10.7224/1537-2073.2013-044

69. Lynch L, Long M, Moorhead A. Young men, help-seeking, and mental health services: exploring barriers and solutions. Am J Mens Health. 2018;12(1):138-149. doi:10.1177/1557988315619469

70. Yousaf O, Grunfeld EA, Hunter MS. A systematic review of the factors associated with delays in medical and psychological helpseeking among men. Health Psychol Rev. 2015;9(2):264-276. doi:10.1080/17437199.2013.840954

71. Cleary A. Help-seeking patterns and attitudes to treatment amongst men who attempted suicide. J Ment Health. 2017;26(3):220-224. doi:10.3109/09638237.2016.1149800

72. Bombardier CH, Blake KD, Ehde DM, Gibbons LE, Moore D, Kraft GH. Alcohol and drug abuse among persons with multiple sclerosis. Mult Scler J. 2004;10(1):35-40. doi:10.1191/1352458504ms989oa

73. Beier M, D'Orio V, Spat J, Shuman M, Foley FW. Alcohol and substance use in multiple sclerosis. J Neurol Sci. 2014;338(12):122-127. doi:10.1016/j.jns.2013.12.029

74. Ying YH, Weng YC, Chang K. The impact of alcohol policies on alcoholattributable diseases in Taiwan-A population-based study. Drug Alcohol Depend. 2017;180:103-112. doi:10.1016/j.drugalcdep.2017.06.044

75. Tsai CP, Lee CT. Impact of disease-modifying therapies on the survival of patients with multiple sclerosis in Taiwan, 1997-2008. Clin Drug Investig. 2013;33(9):647-652. doi:10.1007/s40261-013-0108-7
76. Chung WS, Lin CL, Tsai TC, Hsu WH, Kao CH. Multiple sclerosis increases the risk of venous thromboembolism: a nationwide cohort analysis. Eur J Clin Invest. 2015;45(12):1228-1233. doi:10.1111/ eci. 12502

77. Kang JH, Lin HC. Increased risk of multiple sclerosis after traumatic brain injury: a nationwide population-based study. $J$ Neurotrauma. 2012;29(1):90-95. doi:10.1089/neu.2011.1936

78. Kang JH, Sheu JJ, Kao S, Lin HC. Increased risk of multiple sclerosis following herpes zoster: a nationwide, population-based study. $J$ Infect Dis. 2011;204(2):188-192. doi:10.1093/infdis/jir239

79. Sun LM, Lin CL, Chung CJ, Liang JA, Sung FC, Kao CH. Increased breast cancer risk for patients with multiple sclerosis: a nationwide population-based cohort study. Eur J Neurol. 2014;21(2):238-244. doi:10.1111/ene.12267

80. Tsai CL, Lee JT, Lien LM, et al. The association between septicemia and the risk of multiple sclerosis: a Nationwide Register-based Retrospective Cohort Study in Taiwan. QJM. 2018;111(9):605-611. doi:10.1093/qjmed/hcy123

81. Lai CY, Huang YW, Tseng CH, Lin CL, Sung FC, Kao CH. Patients with carbon monoxide poisoning and subsequent dementia: a Population-Based Cohort Study. Medicine. 2016;95(1):e2418. doi:10.1097/MD.0000000000002418

82. Ministry of Justice. National health insurance act; 2017. Available from: https://law.moj.gov.tw/LawClass/LawAll.aspx?pcode= L0060001. Accessed February 3, 2021.

83. Murphy R, O’Donoghue S, Counihan T, et al. Neuropsychiatric syndromes of multiple sclerosis. J Neurol Neurosurg Psychiatry. 2017;88(8):697-708. doi:10.1136/jnnp-2016-315367

84. Konradi C, Sillivan SE, Clay HB. Mitochondria, oligodendrocytes and inflammation in bipolar disorder: evidence from transcriptome studies points to intriguing parallels with multiple sclerosis. Neurobiol Dis. 2012;45(1):37-47. doi:10.1016/j.nbd.20 11.01 .025

85. Chou IC, Lin HC, Lin CC, Sung FC, Kao CH. Tourette syndrome and risk of depression: a population-based cohort study in Taiwan. $J$ Dev Behav Pediatr. 2013;34(3):181-185. doi:10.1097/DBP.0b013e3 $182829 \mathrm{f} 2 \mathrm{~b}$

86. Cheng CL, Chien HC, Lee CH, Lin SJ, Yang YH. Validity of inhospital mortality data among patients with acute myocardial infarction or stroke in National Health Insurance Research Database in Taiwan. Int J Cardiol. 2015;201:96-101. doi:10.1016/j.ijcard.2015. 07.075

87. Cheng CL, Kao YH, Lin SJ, Lee CH, Lai ML. Validation of the National Health Insurance Research Database with ischemic stroke cases in Taiwan. Pharmacoepidemiol Drug Saf. 2011;20(3):236-242. doi:10.1002/pds.2087

88. Sung SF, Hsieh CY, Lin HJ, Chen YW, Yang YH, Li CY. Validation of algorithms to identify stroke risk factors in patients with acute ischemic stroke, transient ischemic attack, or intracerebral hemorrhage in an administrative claims database. Int $J$ Cardiol. 2016;215:277-282. doi:10.1016/j.ijcard.2016.04.069

89. Tseng HP, Lin FJ, Chen PT, et al. Derivation and validation of a discharge disposition predicting model after acute stroke. $J$ Stroke Cerebrovasc Dis. 2015;24(6):1179-1186. doi:10.1016/j. jstrokecerebrovasdis.2015.01.010

90. Su VY, Liu CJ, Wang HK, et al. Sleep apnea and risk of pneumonia: a nationwide population-based study. CMAJ. 2014;186(6):415-421. doi:10.1503/cmaj.131547

91. Wu CS, Kuo CJ, Su CH, Wang SH, Dai HJ. Using text mining to extract depressive symptoms and to validate the diagnosis of major depressive disorder from electronic health records. J Affect Disord. 2020;260:617-623. doi:10.1016/j.jad.2019.09.044 
92. Wu CS, Lai MS, Gau SS, Wang SC, Tsai HJ. Concordance between patient self-reports and claims data on clinical diagnoses, medication use, and health system utilization in Taiwan. PLoS One. 2014;9(12): e112257. doi:10.1371/journal.pone.0112257

93. Yu ST, Chang HY, Lin MC, Lin YH. Agreement between selfreported and health insurance claims on utilization of health care: A population study. $J$ Clin Epidemiol. 2009;62(12):1316-1322. doi:10.1016/j.jclinepi.2009.01.016

94. Santabarbara J, Lopez-Anton R, de la Camara C, et al. Clinically significant anxiety as a risk factor for dementia in the elderly community. Acta Psychiatr Scand. 2019;139(1):6-14. doi:10.1111/ acps. 12966
95. Santabarbara J, Villagrasa B, Lopez-Anton R, et al. Clinically relevant anxiety and risk of Alzheimer's disease in an elderly community sample: 4.5 years of follow-up. J Affect Disord. 2019;250:16-20. doi:10.1016/j.jad.2019.02.050

\section{Publish your work in this journal}

Neuropsychiatric Disease and Treatment is an international, peerreviewed journal of clinical therapeutics and pharmacology focusing on concise rapid reporting of clinical or pre-clinical studies on a range of neuropsychiatric and neurological disorders. This journal is indexed on PubMed Central, the 'PsycINFO' database and CAS, and is the official journal of The International Neuropsychiatric Association (INA). The manuscript management system is completely online and includes a very quick and fair peer-review system, which is all easy to use. Visit http://www.dovepress.com/testimonials.php to read real quotes from published authors. 